\title{
The Insertion/Deletion Polymorphism of the Angiotensin Converting Enzyme (ACE) in Parkinson's Disease
}

\author{
Spiridon Papapetropoulos* ${ }^{* 1,2}$, Kostantinos Glynos ${ }^{3}$, Zongmin Zhou $^{3}$, Stylianos E Orfanos ${ }^{3}$, Georgia \\ Mitsi $^{4}$ and Andreas Papapetropoulos ${ }^{5}$ \\ ${ }^{1}$ Department of Neurology University of Miami, Miller School of Medicine, USA \\ ${ }^{2}$ Department of Neurology, Regional University Hospital of Patras, Greece \\ ${ }^{3}$ George P. Livanos-Marianthi Simou Laboratories, Department of Critical Care and Pulmonary Services, \\ Evangelismos Hospital, University of Athens School of Medicine, Athens, Greece \\ ${ }^{4}$ University of Miami/Humana Health Research Services, USA \\ ${ }^{5}$ Laboratory of Molecular Pharmacology, Department of Pharmacy, University of Patras, Patras, Greece
}

\begin{abstract}
Parkinson's disease (PDI is a neurodegenerative disorder of unknown etiology. Both genetic and environmental factors are thought to be implicated to some extent. The ACE gene insertion/deletion (I/D) polymorphism has been associated with common neurodegenerative disorders that share similar clinical and neuropathological features with PD (Alzheimer's disease). In this study we set out to examine the role of the ACE gene insertion/deletion (I/D) polymorphism in Parkinson's disease (PD).
\end{abstract}

We conducted a case-control association study among 77 PD patients and 50 non-PD controls from Greece.

The genotype frequencies for II, ID, and DD were 39,48 , and $13 \%$, respectively, in the PD group and 32,50 , and $18 \%$ in the control group. Although the DD frequency was higher in the case group statistical significance was not reached.

We conclude that although disease modifying effects cannot be excluded, the ACE insertion/deletion polymorphism is unlikely to be an important determinant of susceptibility to PD in this population.

Keywords: Angiotensin Converting Enzyme, ACE, Polymorphism, Insertion-deletion, Parkinson's disease, Association study.

\section{INTRODUCTION}

Parkinson's disease (PD) is one of the most common neurodegenerative disorders characterized by selective neurodegeneration, leading to extrapyramidal, hypokinetic motor dysfunction (tremor, rigidity, bradykinesia). However, parkinsonian disorders may present with the additional atypical features of neuropsychiatric (dementia, depression, psychosis) and autonomic involvement. Pathogenic mutations in at least seven different genes are implicated in parkinsonism highlighting the importance of genetic factors and heterogeneous nature of the syndrome [1]. This clinical heterogeneity is also noted with similar characteristics in the presentation of other neurodegenerative disorders like Alzheimer's disease (AD), which share clinical and pathological characteristics with PD [2].

One candidate gene investigated for its relevance in neurodegeneration in both $\mathrm{AD}[3,4]$ and $\mathrm{PD}[5,6]$ is the angiotensin-converting enzyme (ACE). ACE increases blood pressure through conversion of angiotensin I (inactive) to the potent vasoconstrictor angiotensin II [7]. Moreover, ACE is

*Address correspondence to this author at the Department of Neurology, University of Miami, Miller School of Medicine, Clinical Research Building 1120 N.W. 14th Street, 13th Floor Room 1349, Miami, FL 33136, USA; Tel: (+1)(305) 243-8461/(+1)(305) 243-9620; Fax: (+1)(305) 243-3321; E-mail: spapapetropoulos@med.miami.edu a major pathway for the degradation of bradykinin [8], a peptide of the kinin family involved in the regulation of vascular tone that also participates in the peripheral inflammatory response [9]. Apart from angiotensin II and bradykinin, endogenously occurring neuro-peptides, like substance $\mathrm{P}$ and opioid peptides have been identified as ACE substrates. An insertion/deletion (I/D) polymorphism of the ACE gene [10] accounting for half the variance in serum ACE levels has been described. We set out to study this ACE gene polymorphism, in a well characterized cohort of PD patients and aged control subjects.

\section{MATERIALS AND METHODS}

\subsection{Study Population}

The study population consisted of 77 patients with idiopathic PD and 50 controls. PD patients were consecutively recruited in the Department of Neurology of the Regional University Hospital of Patras, Greece (a tertiary referral center) over a period of 2 years. The controls were randomly selected from patients seen in the Regional University Hospital Evagelismos, Athens, Greece and were identified as healthy (no identifiable medical condition including neurological disorder) by their treating physicians. All PD patients and controls were Caucasians, genetically unrelated and of Greek origin. Informed consent was obtained from all the subjects. Diagnosis of PD was made according to the UK PD 
Society Brain Bank diagnostic criteria [11]. Thus, only patients who had bradykinesia and at least two of rigidity, rest tremor and postural instability were included. All patients were investigated with either brain CT or MRI. Cases considered as atypical parkinsonism, vascular parkinsonism, or any PD plus syndrome, were excluded from the study.

During a semi-structured interview demographic data, complete past medical history, age of PD onset, modality of presentation, duration of $\mathrm{PD}$, and dosage of levodopa therapy were collected. The Unified Parkinson's Disease Rating Scale (UPDRS) [12] was completed during clinical examination and was used for evaluation of disease severity. This includes UPDRS I (mentation, behaviour and mood), UPDRS II (activities of daily living), UPDRS III (motor examination), UPDRS IV (complications of therapy), Hoehn \& Yahr scale [13] (measures the severity of the disease and is based on lateralization of the symptoms and balance evaluation) and Schwab \& England scale [14] (also measures activities of daily living).

\subsection{Laboratory Technique}

Genomic DNA was isolated from whole blood using the NucleoSpin Blood L kit (Mecherey - Nagel) following the protocol recommended by the manufacturer. To determine the 287-bp insertion/deletion polymorphism in intron 16 of the ACE gene, a conventional PCR [10] was performed us- ing $500 \mathrm{ng}$ genomic DNA as template with a flanking primer pair 5' CTG GAG ACC ACT CCC ATC CTT TCT 3' and 5' GAT GTG GCC ATC ACA TTC GTC AGA T-3' in a solution of $25 \mu 1$ containing 20 pmol of each primer, $0,5 \mathrm{mM}$ dNTP, $2 \mathrm{mM} \mathrm{Mg}, 10 \mathrm{mM}$ Tris- $\mathrm{HCl}(\mathrm{pH} 8.8), 50 \mathrm{mM} \mathrm{KCl}$, $0.08 \%$ Nonidet P40 and 1unit of Taq DNA Polymerase, (Fermentas, Lithuania). Amplification with this primer pair results in $490 \mathrm{bp}$ and $190 \mathrm{bp}$ products corresponding to I and D alleles, respectively. PCR was carried out on the Robo Cycler 96 (Stratagene, USA) with initial denaturation at 94 ${ }^{\circ} \mathrm{C}$ for $10 \mathrm{~min}$, followed by 30 cycles at $94{ }^{\circ} \mathrm{C}$ for $1 \mathrm{~min}$, at $58{ }^{\circ} \mathrm{C}$ (annealing) for $1 \mathrm{~min}$ and at $72{ }^{\circ} \mathrm{C}$ (extension) for 1 min and then by a final extension period at $72{ }^{\circ} \mathrm{C}$ for $10 \mathrm{~min}$. PCR products were visualised on a $1.5 \%$ agarose-gel containing ethidium bromide. To reduce the incidence of mistyping ID as DD, each DD genotype was subjected to a second run of PCR with a primer pair 5, TGG GAC CAC AGC GCC CGC CAC TAC 3' and 5' TCG CCA GCC CTC CCA TGC CCA TAA 3' that recognizes the insertionspecific sequence with the following program: $10 \mathrm{~min}$ denaturation at $94^{\circ} \mathrm{C}$, followed by 30 cycles at $94{ }^{\circ} \mathrm{C}$ for 50 seconds, at $62{ }^{\circ} \mathrm{C}$ (annealing) for 50 seconds and at $72{ }^{\circ} \mathrm{C}$ (extension) for $1 \mathrm{~min}$. Under these conditions, only the I allele produced a $335 \mathrm{bp}$ amplicon. Genotyping was performed in a blinded fashion with respect to clinical status of patients and controls.

Table 1. ACE Polymorhisms in Patients with Idiopathic Parkinson's Disease (PD) and Non-PD Controls

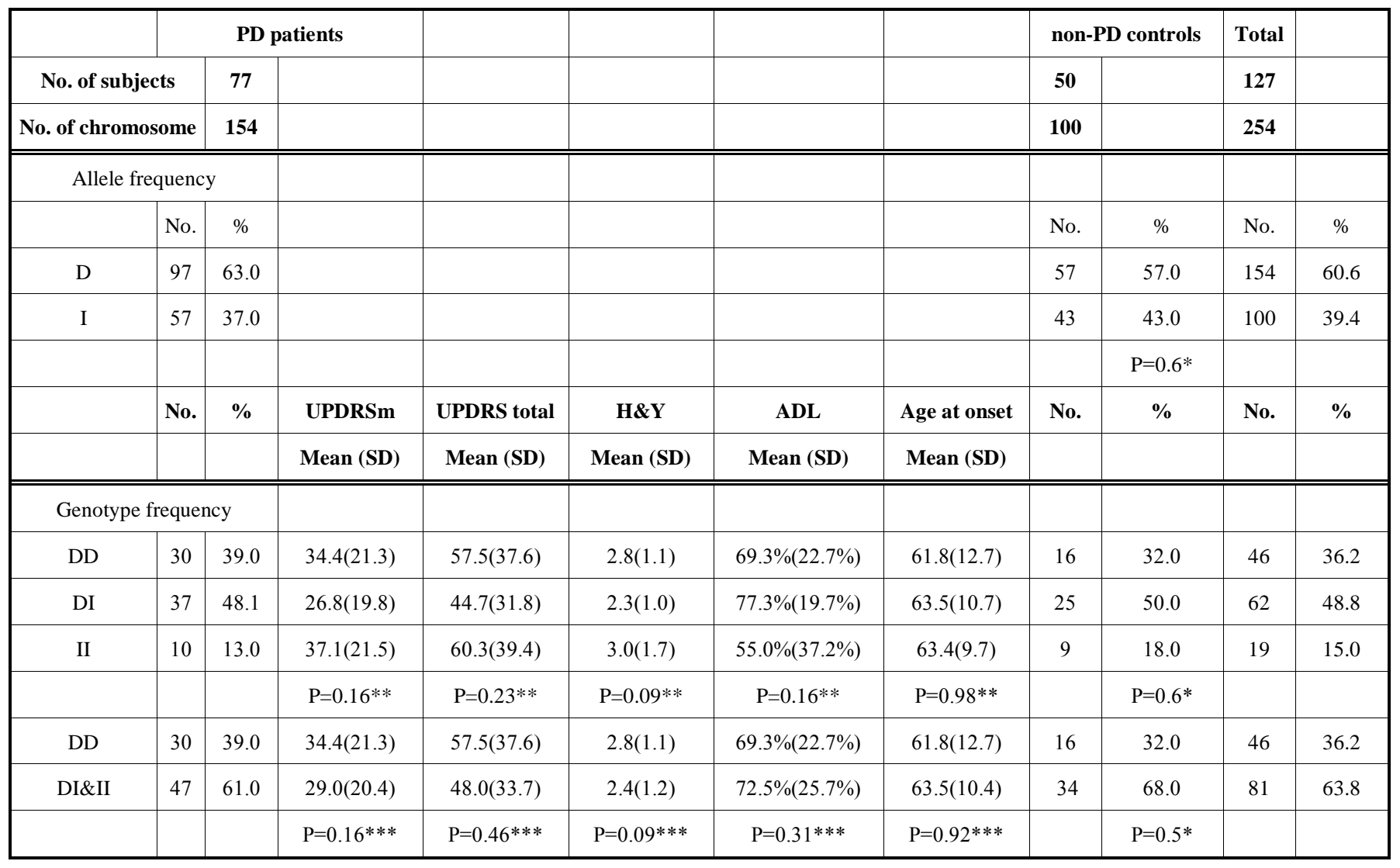

UPDRSm: motor part of the UPDRS scale; H\&Y: Hoehn and Yahr scale; ADL: Activities of daily living scale; SD: standard deviation. $* \mathrm{p}$ value for the comparison of allele frequencies between PD patients and controls.

** $\mathrm{p}$ value for the comparison UPDRSm, UPDRS total, H\&Y, ADL and age at onset between PD patients of different genotype groups (DD, DI, II).

*** $\mathrm{p}$ value for the comparison UPDRSm, UPDRS total, H\&Y, ADL and age at onset between PD patients of different genotype groups (DD vs DI and II)

D/I: deletion/insertion polymorphism; PD: Parkinson's disease. 


\subsection{Statistical Analysis}

Statistical analysis was performed using the SPSS for Windows release 11.0, run on an IBM-compatible computer. Mann-Whitney $U$ test for two samples was used in nonparametric comparisons of continuous data. Chi-square with Yates's corrected p-value and 2-tailed Fischer's exact test were used, as appropriate, for the comparison of proportions. For corrections of associations, multivariate analysis was performed using stepwise logistic regression. Adjustments were made for gender, age at onset and disease stage. The level of statistical significance was set at $p<0.05$. The study was approved by the local Institutional Review Board (IRB).

\section{RESULTS}

Our study population consisted of 77 PD patients (43 men and 34 women), age 35 to 89 years with the mean of 69.2 (SD 10.4) years, and 50 control subjects (35 men and 15 ) women, age 19 to 80 years with the mean of 49.5 (SD 21.6) years. PD patients had a mean age of onset of 62.84 (SD11.30) years (the age at onset of PD was defined as the appearance of the first symptom estimated by medical interview). The mean duration of symptoms was 6.27 (SD 5.28) years.

The ACE I/D polymorphism genotypes and allele frequencies are presented in Table 1. The distribution of II, ID and DD genotypes was not significantly different between PD patients and control subjects $(\mathrm{p}=0.6)$. The most frequent genotype was ID. There were fewer II genotypes $10(13.0 \%)$ and more DD genotypes $30(39.0 \%)$ in the PD patients. ACE genotypes for our cohort, PD cases and controls independently, were in Hardy-Weinberg equilibrium. The D and I allele distributions in the PD and control groups also revealed no significant differences $(\mathrm{p}=0.6)$. The $\mathrm{D}$ alleles were more common in both groups $(63.0 \%$ in the PD group and $57.0 \%$ in the control group). No significant associations were observed when adjustment using stepwise logistic regression was applied $(\mathrm{p}<0.05)$.

The most predominant symptoms at onset were bradykinesia or rigidity related. At the time of examination, the mean total UPDRS was 51.7 (SD 35.4). The UPDRS subscores were: UPDRSI 6.27 (SD 3.53), UPDRSII 15.82 (SD
11.16), UPDRSII (or UPDRSm) 31.09 (SD 20.79), UPDRSIV 2.52 (SD 3.95). The mean Hoehn \& Yahr score was 2.56 (SD 1.14) and mean Swab \& England score was $71.30 \%$ (SD24.46\%). The main symptoms of PD at onset and examination, and the L-dopa induced motor side effects (dyskinesias, wearing-off and on-off phenomena), the vascular comorbid conditions (ischemic heart disease and cerebrovascular disease) and family history of PD patients are presented in Table 2 . The subgroup analysis of main PD symptoms and L-dopa motor side effects according to the presence or absence of the DD genotype (Table 2) revealed higher frequency of the DD phenotype in patients with the akinetic-rigid form of the disease and L-dopa induced motor complications. These differences were not statistically significant. When results were analyzed by groups defined by phenotype and not by genotype, a marginally non-significant result was revealed: there were only 9 DD homozygotes $(26.5 \%)$ in the patients with an initial tremor-dominant form of PD $(n=34)$ compared to 21 DD homozygotes $(48.8 \%)$ in the bradykinesia-rigidity dominant form $(n=43)$ (Fisher exact test $\mathrm{p}=0.061$ and Pearson $\chi^{2}$ test $\mathrm{p}=0.061$ ).

Finally, we compared the distribution of the genotypes (DD, ID, II) in PD patients and control subjects categorized by age group. For PD patients we used the age of onset (age $<50,50-59,60-69$ and $\geq 70$ years). No statistically significant differences were noted in the age subgroup analysis although patients with younger onset PD tended to have the DD phenotype more frequently. The results of this analysis are presented in Table $\mathbf{3}$.

\section{DISCUSSION}

The ACE gene is located on chromosome 17q23 and consists of 26 exons and 25 introns. While ACE is best known for the conversion of angiotensin I to angiotensin II and for the degradation of bradykinin, this dipeptidyl carboxypeptidase has additional substrates. A substrate of special interest with regard to PD is substance P [15], an undecapeptide that displays neuroprotective effects [16-18]. Substance $\mathrm{P}$ also increases rat locomotor activity when microinjected into discrete regions of the basal ganglia including the substantia nigra reticulata ( $\mathrm{SNr}$ ), substantia nigra compacta $(\mathrm{SNc})$, ventral tegmental area (VTA), and globus pallidum

Table 2. Subgroup Analys is of Main PD Symptoms and L-Dopa Motor Side Effects According to ACE Genotypes

\begin{tabular}{|c|c|c|c|c|c|}
\hline & $\mathbf{N}(\mathbf{n}=77, \%$ of total $) *$ & $\mathbf{D D}(\%)^{* *}$ & $\mathbf{D I}(\%) * *$ & $\mathbf{I I}(\%)^{* *}$ & p-value \\
\hline \multicolumn{6}{|l|}{ Initial Symptoms } \\
\hline Tremor dominant & $34(44.2 \%)$ & $9(30.0 \%)$ & $20(54.1 \%)$ & $5(50.0 \%)$ & \multirow[t]{2}{*}{0.13} \\
\hline B-R dominant & $43(55.8 \%)$ & $21(70.0 \%)$ & $17(45.9 \%)$ & $5(50.0 \%)$ & \\
\hline Tremor at examination & $52(67.5 \%)$ & $18(60.0 \%)$ & $28(75.7 \%)$ & $6(60.0 \%)$ & 0.34 \\
\hline Rigidity at examination & $58(75.3 \%)$ & $23(76.7 \%)$ & $27(73.0 \%)$ & $8(80.0 \%)$ & 0.88 \\
\hline Instability at examination & $38(49.4 \%)$ & $18(60.0 \%)$ & $14(37.8 \%)$ & $6(60.0 \%)$ & 0.15 \\
\hline Dyskinesias & $15(19.5 \%)$ & $7(23.3 \%)$ & $5(13.5 \%)$ & $3(30.0 \%)$ & 0.40 \\
\hline On-off phenomena & $22(28.6 \%)$ & $13(43.3 \%)$ & $6(16.2 \%)$ & $3(30.0 \%)$ & 0.06 \\
\hline
\end{tabular}

B-R: bradykinesia rigidity; DI: deletion/insertion polymorphism; PD: Parkinson's disease.

*Percentage $(\%)$ of all PD patients.

**Percentage of PD patients with each genotype. 
Table 3. Comparison ACE Genotypes in PD Patients and Control Subjects Categorized by Age Group

\begin{tabular}{|c|c|c|c|c|c|c|c|c|c|}
\hline & \multicolumn{2}{|c|}{$\begin{array}{l}\text { PD group } \\
(\mathrm{N}=77)\end{array}$} & \multirow[b]{2}{*}{ DI } & \multirow[b]{2}{*}{ II } & \multicolumn{2}{|c|}{$\begin{array}{l}\text { Control subjects } \\
\qquad(\mathrm{N}=50)\end{array}$} & \multirow[b]{2}{*}{ DI } & \multirow[b]{2}{*}{ II } & \multirow[t]{2}{*}{ p-value } \\
\hline & $\mathrm{N}$ & DD & & & $\mathrm{N}$ & DD & & & \\
\hline Total & 77 & $30(39.0 \%)$ & $37(48.0 \%)$ & $10(13.0 \%)$ & 50 & $16(32.0 \%)$ & $25(50.0 \%)$ & $9(18.0 \%)$ & 0.63 \\
\hline$<50$ & 12 & $7(58.3 \%)$ & $4(33.3 \%)$ & $1(8.3 \%)$ & 25 & $9(36.0 \%)$ & $11(44.0 \%)$ & $5(20.0 \%)$ & 0.40 \\
\hline $50-59$ & 11 & $1(9.1 \%)$ & $7(63.3 \%)$ & $3(27.3 \%)$ & 3 & $0(0.0 \%)$ & $1(33.3 \%)$ & $2(66.7 \%)$ & 0.43 \\
\hline $60-69$ & 30 & $12(40.0 \%)$ & $15(50.0 \%)$ & $3(10.0 \%)$ & 10 & $2(20.0 \%)$ & $7(70.0 \%)$ & $1(10.0 \%)$ & 0.50 \\
\hline$\geq 70$ & 24 & $10(41.7 \%)$ & $11(45.8 \%)$ & $3(12.5 \%)$ & 12 & $5(41.7 \%)$ & $6(50.0 \%)$ & $1(8.3 \%)$ & 0.93 \\
\hline
\end{tabular}

D/I: deletion/insertion polymorphism; PD: Parkinson's disease.

(GP) [19-22]. Several studies in rats have also shown that the substance $P$ can increase dopamine outflow [23-27] as well as acetylcholine release [28] under normal conditions.

A deletion/insertion (D/I) polymorphism of ACE has been reported that arises from the presence or absence of a 287-base pair sequence of intron 16 resulting in three genotypes (DD/II homozygotes and ID heterozygote) [29]. Although ACE activity is found in plasma, the majority of the biologically active enzyme is tissue-bound [30]. Tiret et al. [31] provided evidence that the insertion/deletion (ID) polymorphism is associated with higher plasma ACE activity. Later reports established that the DD genotype is also associated with a higher tissue ACE activity [32]. As reduced neuroprotection is implicated in the pathogenesis of PD [33], one could speculate that the increased ACE activity in subjects with a DD genotype could lower the levels of substance $\mathrm{P}$, making them more susceptible to PD. Lower levels of substance $\mathrm{P}$ may also affect locomotion and dopamine modulatory mechanisms further contributing to the development of PD. Interestingly, substance P levels and immunoreactivity are decreased in nigral and striatal tissues of animals models of PD and in postmortem samples of PD patients [16].

To test the hypothesis that the ACE I/D polymorphism is associated with $\mathrm{PD}$, possibly through altering substance $\mathrm{P}$ levels, we determined ACE genotypes in PD patients and compared them to non-PD controls. The frequency of the DD genotype and the D allele was higher in the PD population. The frequency of the DD phenotype was also higher in younger patients and in patients with the akinetic-rigid type of PD. However, statistical significance was not reached in any of the comparisons made throughout our study. However, the marginally non-significant increased prevalence of DD homozygotes in the akinetic-rigid predominant PD patients may suggest that the I/D polymorphism has disease modifying effects. Mellick et al. [6] were the first to investigate the possible involvement of the ACE gene in the pathogenesis of PD in a population of Caucasians. Based on evidence linking the DD ACE genotype to longevity [34] they suggested that D allele may confer some long-term protective effect as a result of ACE' s action on neuropeptides and neuroendocrine function. In their study similar frequencies were reported for the D and I alleles in the PD (D $48 \%$ and I $52 \%$ ) and control population (D 54\% and I 46\%). Furthermore, the genotype distribution was also similar in the PD and control group (the most frequent phenotype was ID in $52 \%$ of PD patients and $56 \%$ of controls). Our results are in agreement with those of Mellick et al. that also failed to provide evidence that the ACE polymorphism is related to PD. Both our studies report similar allele frequencies in the control groups confirming previous results (the reported D allele frequency in Caucasians is $50-58 \%[35,36]$.

In a different study, Lin et al. [5] also evaluated the possible relationship between the ACE polymorphism and PD in a Chinese population. The frequency of the homozygote DD genotype of the ACE gene was increased in the PD group ( $22 \%$ in the PD vs $12 \%$ in the control group), but the statistical significance was marginal $(p=0.048)$. The increase in the DD genotype in the PD group was also noted in our study (39\% in the PD vs $32 \%$ in the control group) but significance was not reached. One could speculate that various reasons like ethnicity, (Caucasians and Chinese have different genetic backrounds), sample size and different recruitment methods used for the control population could account for this difference in significance between the two studies. In normal Chinese the D allele frequency is 35-39\% [36]. The frequency of $\mathrm{D}$ allele in the control subjects in the study by Lin et al. $(33 \%)$ was markedly different from that in our report $(57 \%)$ and Mellick's study (54\%). However, this is in accordance with the frequencies of the D allele in Caucasian and Chinese populations.

Our study has certain strengths and limitations. We acknowledge the relatively small sample size and highlight the preliminary nature of these findings. Strengths of our study include its prospective nature and the homogeneity of the sample population.

Based on the evidence presented herein, we conclude that the ACE insertion/deletion polymorphism is not associated with PD and that ACE genotypes do not correlate significantly with any of the symptoms of the disease in Caucasians, although a disease modifying effect cannot be excluded. Our data suggest that ACE genotype is unlikely to be an important determinant of susceptibility to PD.

\section{ACKNOWLEDGEMENTS}

We would like to thank the participants and their families for making these studies possible. 


\section{REFERENCES}

[1] Farrer MJ. Genetics of Parkinson disease: paradigm shifts and future prospects. Nat Rev Genet 2006; 7(4): 306-18.

[2] Papapetropoulos S, Lieberman A, Gonzalez J, Mash DC. Can Alzheimer's type pathology influence the clinical phenotype of Parkinson's disease? Acta Neurol Scand 2005; 111(6): 353-9.

[3] Kolsch H, Jessen F, Freymann N, et al. ACE I/D polymorphism is a risk factor of Alzheimer's disease but not of vascular dementia. Neurosci Lett 2005; 377(1): 37-9.

[4] Meng Y, Baldwin CT, Bowirrat A, et al. Association of polymorphisms in the Angiotensin-converting enzyme gene with Alzheimer disease in an Israeli Arab community. Am J Hum Genet 2006; 78(5): 871-7.

[5] Lin JJ, Yueh KC, Chang DC, Lin SZ. Association between genetic polymorphism of angiotensin-converting enzyme gene and Parkinson's disease. J Neurol Sci 2002; 199(1-2): 25-9.

[6] Mellick GD, Buchanan DD, McCann SJ, et al. The ACE deletion polymorphism is not associated with Parkinson's disease. Eur Neurol 1999; 41(2): 103-6.

[7] Timmermans PB, Wong PC, Chiu AT, et al. Angiotensin II receptors and angiotensin II receptor antagonists. Pharmacol Rev 1993; 45(2): 205-51.

[8] Atlas SA. The renin-angiotensin system revisited: classical and nonclassical pathway of angiotensin formation. Mt Sinai J Med 1998; 65(2): 87-96.

[9] Reiser G, Binmoller FJ, Donie F. Mechanisms for activation and subsequent removal of cytosolic $\mathrm{Ca} 2+$ in bradykinin-stimulated neuronal and glial cell lines. Exp Cell Res 1990; 186(1): 47-53.

[10] Rigat B, Hubert C, Alhenc-Gelas F, Cambien F, Corvol P, Soubrier F. An insertion/deletion polymorphism in the angiotensin Iconverting enzyme gene accounting for half the variance of serum enzyme levels. J Clin Invest 1990; 86(4): 1343-6.

[11] Hughes AJ, Daniel SE, Kilford L, Lees AJ. Accuracy of clinical diagnosis of idiopathic Parkinson's disease: a clinico-pathological study of 100 cases. J Neurol Neurosurg Psychiatry 1992; 55(3): 181-4.

[12] Fahn S, Elton RL, Members of the UPDRS Development Committee. Unified Parkinson's Disease Rating Scale. In: Fahn S, Marsden CD, Calne DB, Eds. Recent developments in Parkinson's disease. 2nd ed. Florham Park, NJ: Macmillan Health Care Information; 1987; 153-164.

[13] Hoehn MM, Yahr MD. Parkinsonism: onset, progression and mortality. Neurology 1967; 17(5): 427-42.

[14] Schwab RS, England AC. Projection technique for evaluating surgery in Parkinson's disease. In: Gillingham FD, IMl, Ed. Third symposium of Parkinson's disease. Edinburgh: Livingstone 1969; 152-7.

[15] Skidgel RA, Defendini R, Erdos EG. Angiotensin I converting enzyme and its role in neuropeptide metabolism. In: Turner AJ, Ed. Neuropepetides and their peptidases. New York: Ellis Horwood 1987; 165-82.

[16] Chen LW, Yung KK, Chan YS. Neurokinin peptides and neurokinin receptors as potential therapeutic intervention targets of basal ganglia in the prevention and treatment of Parkinson's disease. Curr Drug Targets 2004; 5(2): 197-206.

[17] Sanberg PR, Emerich DF, Aebischer P, et al. Substance P containing polymer implants protect against striatal excitotoxicity. Brain Res 1993; 628(1-2): 327-9.

[18] Barker R. Substance P and Parkinson's disease: a causal relationship? J Theor Biol 1986; 120(3): 353-62.
[19] Kalivas PW, Deutch AY, Maggio JE, Mantyh PW, Roth RH. Substance $\mathrm{K}$ and substance $\mathrm{P}$ in the ventral tegmental area. Neurosci Lett 1985; 57(3): 241-6.

[20] Kelley AE, Cador M, Stinus L. Behavioral analysis of the effect of substance $\mathrm{P}$ injected into the ventral mesencephalon on investigatory and spontaneous motor behavior in the rat. Psychopharmacology (Berl) 1985; 85(1): 37-46.

[21] Stoessl AJ, Szczutkowski E, Glenn B, Watson I. Behavioural effects of selective tachykinin agonists in midbrain dopamine regions. Brain Res 1991; 565(2): 254-62.

[22] Napier TC, Mitrovic I, Churchill L, Klitenick MA, Lu XY, Kalivas $\mathrm{PW}$. Substance $\mathrm{P}$ in the ventral pallidum: projection from the ventral striatum, and electrophysiological and behavioral consequences of pallidal substance P. Neuroscience 1995; 69(1): 59-70.

[23] Furmidge LJ, Duggan AW, Arbuthnott GW. Substance P release from rat nucleus accumbens and striatum: an in vivo study using antibody microprobes. Brain Res 1993; 610(2): 234-41.

[24] Khan S, Brooks N, Whelpton R, Michael-Titus AT. Substance P(1-7) and substance P-(5-11) locally modulate dopamine release in rat striatum. Eur J Pharmacol 1995; 282(1-3): 229-33.

[25] Glowinski J, Kemel ML, Desban M, et al. Distinct presynaptic control of dopamine release in striosomal- and matrix-enriched areas of the rat striatum by selective agonists of NK1, NK2 and NK3 tachykinin receptors. Regul Pept 1993; 46(1-2): 124-8.

[26] Tremblay L, Kemel ML, Desban M, Gauchy C, Glowinski J. Distinct presynaptic control of dopamine release in striosomal- and matrix-enriched areas of the rat striatum by selective agonists of NK1, NK2, and NK3 tachykinin receptors. Proc Natl Acad Sci USA 1992; 89(23): 11214-8.

[27] Kemel ML, Desban M, Glowinski J, Gauchy C. Distinct presynaptic control of dopamine release in striosomal and matrix areas of the cat caudate nucleus. Proc Natl Acad Sci USA 1989; 86(22): 9006-10.

[28] Anderson JJ, Chase TN, Engber TM. Substance P increases release of acetylcholine in the dorsal striatum of freely moving rats. Brain Res 1993; 623(2): 189-94.

[29] Rigat B, Hubert C, Corvol P, Soubrier F. PCR detection of the insertion/deletion polymorphism of the human angiotensin converting enzyme gene (DCP1) (dipeptidyl carboxypeptidase 1). Nucleic Acids Res 1992; 20(6): 1433.

[30] Esther CR, Marino EM, Howard TE, et al. The critical role of tissue angiotensin-converting enzyme as revealed by gene targeting in mice. J Clin Invest 1997; 99(10): 2375-85.

[31] Tiret L, Rigat B, Visvikis S, et al. Evidence, from combined segregation and linkage analysis, that a variant of the angiotensin Iconverting enzyme (ACE) gene controls plasma ACE levels. Am J Hum Genet 1992; 51(1): 197-205.

[32] Danser AH, Schalekamp MA, Bax WA, et al. Angiotensinconverting enzyme in the human heart. Effect of the deletion/insertion polymorphism. Circulation 1995; 92(6): 1387-8.

[33] Mandel S, Grunblatt E, Riederer P, Gerlach M, Levites Y, Youdim MB. Neuroprotective strategies in Parkinson's disease : an update on progress. CNS Drugs 2003; 17(10): 729-62.

[34] Schachter F, Faure-Delanef L, Guenot F, et al. Genetic associations with human longevity at the APOE and ACE loci. Nat Genet 1994; 6(1): 29-32.

[35] Lin JJ, Yueh KC, Harn HJ, Chang DC, Chang CY, Yeh YH. Lack of association between deletion polymorphism of the ACE gene and ischemic vascular diseases in a Chinese population in Taiwan. Zhonghua Yi Xue Za Zhi (Taipei) 1999; 62(11): 756-63.

[36] Sharma P. Meta-analysis of the ACE gene in ischemic stroke. J Neurol Neurosurg Psychiatry 1998; 64: 227-30.

(C) Papapetropoulos et al.; Licensee Bentham Open.

This is an open access article licensed under the terms of the Creative Commons Attribution Non-Commercial License (http://creativecommons.org/licenses/by-nc/3.0/) which permits unrestricted, non-commercial use, distribution and reproduction in any medium, provided the work is properly cited. 